\title{
The Impact of High-Flow Nasal Oxygen in the Immunocompromised Critically Ill: A Systematic Review and Meta-Analysis
}

\author{
Michael C Sklar MD, Alaa Mohammed MD, Ani Orchanian-Cheff MISt, Lorenzo Del Sorbo MD, \\ Sangeeta Mehta MD, and Laveena Munshi MD MSc
}

\begin{abstract}
BACKGROUND: High-flow nasal-cannula (HFNC) may be an oxygen modality useful for preventing invasive mechanical ventilation and mortality; however, its role in acute hypoxemic respiratory failure is not clearly defined. We sought to evaluate the impact of HFNC on mortality across immunocompromised subjects compared to alternative noninvasive oxygen therapies, namely conventional oxygen therapy and noninvasive ventilation (NIV). METHODS: We systematically searched the major databases to identify randomized, controlled trials (RCTs) or observational studies (until May 2018). We included studies reporting the use of HFNC in immunocompromised subjects and evaluated its impact on mortality and invasive mechanical ventilation. RESULTS: Upon review of 6,506 titles, 13 studies (1,956 subjects) fulfilled our inclusion criteria (4 RCTs, 9 observational studies). The predominant cause of immunocompromised status was cancer. Bacterial pneumonia was the most common cause of acute hypoxemic respiratory failure with a median $\mathrm{P}_{\mathrm{aO} 2} / \mathrm{F}_{\mathrm{IO} 2}$ of $145 \mathrm{~mm} \mathrm{Hg}$ (interquartile range 115-175). HFNC was used as the first oxygen strategy in 474 subjects compared to NIV (242 subjects) and conventional $O_{2}$ therapy (703 subjects). There was a $46 \%$ rate of invasive mechanical ventilation and $36 \%$ mortality. Mortality at the longest available follow-up was lower with HFNC compared to the oxygen therapy controls (NIV or conventional $\mathrm{O}_{2}$ therapy) in 7 studies $(1,429$ subjects; relative risk $0.72,95 \%$ CI $0.56-0.93, P=.01)$. There was a lower rate of invasive mechanical ventilation with HFNC compared to the oxygen therapy controls across 8 studies $(1,529$ subjects, relative risk $0.81,95 \%$ CI $0.67-0.96, P=.02)$. These results were robust across a series of sensitivity analyses. CONCLUSIONS: There exists a need to develop a greater evidence base evaluating the utility of HFNC in immunocompromised subjects. In our exploratory analysis, HFNC was found to decrease mortality and use of invasive mechanical ventilation compared to alternative noninvasive oxygen controls. These results are meant to be exploratory. Higher-quality studies evaluating a more homogeneous population are needed to further elucidate its benefit. Key words: high-flow nasal oxygen; noninvasive ventilation; oncology; immunosuppressed; acute respiratory failure. [Respir Care 2018;63(12):1555-1566. ( 2018 Daedalus Enterprises]
\end{abstract}

\section{Introduction}

Acute hypoxemic respiratory failure (AHRF) is the most common cause of critical illness in immunocompromised

\footnotetext{
Dr Sklar is affiliated with the Department of Anesthesiology, University of Toronto, Ontario, Canada. Drs Sklar, Mohammed, Del Sorbo, Mehta, and Munshi are affiliated with the Interdepartmental Division of Critical Care Medicine, Sinai Health System/University Health Network, University of Toronto, Ontario, Canada. Ms Orchanian-Cheff is affiliated with Library and Information Services, University Health Network, Toronto, Ontario, Canada.
}

The authors have disclosed no conflicts of interest. patients. ${ }^{1}$ Patients who progress to require invasive mechanical ventilation are subject to increased mortality. ${ }^{2}$ Increased mortality may be attributed to many factors,

\footnotetext{
Supplementary material related to this paper is available at http:// www.rcjournal.com.

Correspondence: Laveena Munshi MD MSc, Interdepartmental Division of Critical Care Medicine, Mount Sinai Hospital, Sinai Health System, University of Toronto, 600 University Ave, Toronto, ON M5G 1X5, Canada. E-mail: laveena.munshi@sinaihealthsystem.ca.
}

DOI: $10.4187 /$ respcare. 05962 
including aggressive or drug-resistant pathogens, greater frailty at the time of ICU admission, and host response. ${ }^{3-5}$

In hypoxemic immunocompromised patients, noninvasive oxygen therapy may be delivered via simple face mask (conventional oxygen therapy), through noninvasive ventilation (NIV), or with a high-flow nasal cannula (HFNC). Although earlier studies in immunocompromised subjects receiving NIV compared to conventional $\mathrm{O}_{2}$ therapy suggested a reduced need for intubation, these results have been called into question in recent years. ${ }^{6-8}$ One trial included a predominantly solid organ transplant population with pulmonary edema, for which there is ample evidence of benefit of $\mathrm{NIV}^{7}$; another trial was composed of subjects with hematologic malignancy who had a mortality rate in excess of $80 \%$, a finding that has changed in recent years. ${ }^{6}$ These findings have been challenged by more recent evidence suggesting a lack of benefit with NIV. ${ }^{8-11}$

The HFNC is a newer device that has recently been shown to provide a survival benefit in critically ill, nonimmunocompromised, hypoxemic patients compared to use of NIV or conventional $\mathrm{O}_{2}$ therapy. ${ }^{12}$ However, this evidence has been inconsistent across the literature. ${ }^{13,14}$ The mechanisms of effect that lead to better oxygenation include washout of $\mathrm{CO}_{2}$ from the anatomical dead space, generation of PEEP, and more stable $\mathrm{F}_{\mathrm{IO}_{2}}$ due to the higher flows administered. ${ }^{15,16}$ Furthermore, in contrast to lowflow systems, heated humidification prevents airway dryness, preserving mucociliary function and enhancing clearance of secretions. ${ }^{15,16}$

It is unclear whether these promising results with HFNC translate to the immunocompromised population. With the goal to reserve intubation in those failing noninvasive oxygenation strategies, there is a need to better understand these therapies in this unique population. Therefore, we undertook a systematic review to review the body of literature to date (as of May 2018) to examine the use of HFNC compared to other modalities of oxygenation in immunocompromised subjects with AHRF. We evaluated the data for homogeneity and considered performing a meta-analysis to determine the impact of HFNC on mortality and invasive mechanical ventilation. Any meta-analyses performed are intended only for the generation of hypotheses.

\section{Methods}

\section{Search Strategy}

A comprehensive search strategy was developed to identify published literature on the use of HFNC (see the supplementary materials at http://www.rcjournal.com). At the time of the search, specific subject headings for high-flow therapy were unavailable in the databases used. The strat- egy was devised using an extensive list of appropriate text words and phrases. Key words were either mined from sample articles and product descriptions or generated through input from subject specialists on the team. The search was not focused on any particular population, outcome, or study type to keep it sufficiently sensitive.

The following databases were searched from inception through May 15, 2018: MEDLINE, MEDLINE In-Process \& Other Non-Indexed Citations, Embase, Cochrane Database of Systematic Reviews, Cochrane Central Register of Controlled Clinical Trials, and CINAHL. Additionally, we searched a clinical trials registry (http://clinicaltrials.gov) for unpublished and ongoing studies. A supplementary search was conducted in PubMed for non-MEDLINE records. No language restrictions were applied.

\section{Study Selection}

Eligibility was determined by 2 reviewers (MCS, AM). Studies of HFNC for AHRF including only immunocompromised subjects were independently selected and reviewed by reviewers. Disagreements were resolved by consensus or in discussion with a senior author (LM). We included any observational studies or randomized, controlled trials (RCTs) of adult immunocompromised subjects undergoing HFNC for AHRF. RCTs were included if HFNC was compared to NIV or conventional $\mathrm{O}_{2}$ therapy. If both HFNC and NIV were included in a cohort, the cohort was categorized based upon which modality predominated in a 24 -h period. We excluded pediatric studies and studies involving the application of HFNC in the postextubation or peri-procedural setting.

\section{Study Outcomes}

After our descriptive review, we inspected each study for clinical heterogeneity to evaluate the feasibility of performing a meta-analysis. Our primary outcome of interest was mortality at the longest available time point reported comparing HFNC to any oxygen therapy control (ie, a combination of NIV or conventional $\mathrm{O}_{2}$ therapy). Secondary outcomes included the rate of invasive mechanical ventilation for HFNC compared to an oxygen therapy control (NIV or conventional $\mathrm{O}_{2}$ therapy) during that hospitalization. We conducted subgroup analyses evaluating mortality and invasive mechanical ventilation in the subgroups of the oxygen therapy control (HFNC vs NIV and HFNC vs conventional $\mathrm{O}_{2}$ therapy). We performed a sensitivity analysis restricting the meta-analysis to RCTs and observational studies that used propensity-score matching. Finally, across studies that conducted multivariable analysis, we evaluated factors that were found to be statistically significantly associated with mortality and invasive mechanical ventilation across this population. 


\section{Data Abstraction and Study Quality}

Data from included studies were independently abstracted by the reviewers using a standardized data collection form. Study design, patient demographics, immunocompromised status, characteristics of oxygen delivery methods, and patient outcomes were collected. Two authors (MCS and AM) independently assessed potential sources of bias using the Cochrane Collaboration Risk of Bias Tool ${ }^{17}$ for RCTs and the Newcastle-Ottawa Scale for observational studies. ${ }^{18}$

\section{Data Analysis}

Data were summarized using medians and interquartile ranges (IQRs) or mean $\pm \mathrm{SD}$ where appropriate. For the meta-analyses, we compared HFNC to oxygen therapy control (combination of conventional $\mathrm{O}_{2}$ therapy or NIV) for our primary analysis. Meta-analysis included RCTs or any observational studies and were weighted using the inverse variance method. Categorical outcomes were evaluated using relative risk (RR). Study results were pooled using Review Manager (RevMan version 5.2; Cochrane Collaboration, Oxford, United Kingdom) with a 2-sided significance level of 5\%. Individual study and summary results are reported with risk ratios and 95\% CIs. Random effects models were used for all analyses. ${ }^{19}$ Statistical heterogeneity among trials was assessed using the $\mathrm{I}^{2}$ statistic, defined as the percentage of total variability across studies attributable to heterogeneity rather than chance, and using published guidelines for low $\left(\mathrm{I}^{2}=25-49 \%\right)$, moderate $\left(\mathrm{I}^{2}=50-74 \%\right)$, and high $\left(\mathrm{I}^{2} \geq 75 \%\right)$ heterogeneity. ${ }^{20}$

\section{Results}

\section{Search Results}

Our search strategy identified 6,506 citations. Further screening of 223 full texts yielded a total of 13 studies that fulfilled our inclusion criteria and focused on immunocompromised subjects (see PRISMA Flow Diagram in the supplementary materials at http://www.rcjournal.com). ${ }^{21-33}$

\section{Characteristics of Included Studies}

Thirteen studies reporting on 1,956 subjects were included in this systematic review. The studies included 8 retrospective, cohort studies (532 subjects), 22-24,27,30-33 1 prospective observational study (915 subjects, 859 of whom were appropriate for analysis), ${ }^{21}$ and 4 RCTs, 2 of which were post hoc analyses of previous RCTs (565 subjects) (Table 1). ${ }^{25,26,28,29}$ Two of the observational studies and 1 post hoc analysis of a previous RCT used propensityscore matching techniques. ${ }^{28,29,31}$ Nine studies compared
HFNC to an oxygen therapy control (3 NIV/conventional $\mathrm{O}_{2}$ therapy, $3 \mathrm{NIV}, 3$ conventional $\mathrm{O}_{2}$ therapy). Outcomes of interest for our meta-analysis were reported in 8 studies (1,529 subjects, 3 RCTs, 1 prospective observational study, 4 retrospective cohort studies). ${ }^{21,24,26-29,31,32}$ The 4 RCTs were not considered to be at high risk of bias; however, they were unblended, and 2 of the 4 were post hoc analyses of randomized trials. ${ }^{28,29}$ The observational studies were of moderate to high quality with 6-9 points awarded on the Newcastle Ottawa Scale (see the supplementary materials at http://www.rcjournal.com).

\section{Immunocompromised Population and Acute Hypoxic Respiratory Failure}

The leading cause of immunosuppression was related to an oncologic diagnosis with a predominance of hematologic malignancy (11 of 13 studies). Two studies focused primarily on solid organ transplant. ${ }^{24,32}$ Infectious pneumonia (mainly bacterial) was the predominant cause of respiratory failure across this cohort (49-83\%). Fungal infections, where reported, were found in $3-15 \%$ of cases. Opportunistic infections, particularly Pneumocystis jirovecii pneumonia, were reported in $7-24 \%$ of cases and was the primary focus of 1 study. ${ }^{33}$ The rates of no diagnosis for AHRF ranged from $4 \%$ to $13 \%$.

There existed variable definitions of AHRF (Table 3), with most subjects demonstrating moderate hypoxia despite supplemental oxygen or tachypnea. HFNC was initiated in the emergency department, acute care ward, or ICU, with the latter being the most common site of initiation (10 of 13 studies). The median $\mathrm{P}_{\mathrm{aO}_{2}} / \mathrm{F}_{\mathrm{IO}_{2}}$ across the studies was $145 \mathrm{~mm} \mathrm{Hg}$ (IQR 115-175). The duration of HFNC therapy varied widely, ranging from $2 \mathrm{~h}$ to $80 \mathrm{~h}$. HFNC $\mathrm{F}_{\mathrm{IO}_{2}}$ ranged from 0.60 to 1.00 with flows of 21 $60 \mathrm{~L} / \mathrm{min}$ (Table 3). Rates of intubation varied across the studies given the variable time points of assessment. In 1 study, the need for intubation was reported at $9 \% 24 \mathrm{~h}$ after HFNC initiation. ${ }^{26}$ For the remaining studies that evaluated intubation rates at $28 \mathrm{~d}$ or hospital discharge, a median intubation rate of $46 \%$ (IQR 25-67\%) was reported. The longest follow-up mortality time points are reported in Table 3 with a median mortality of $36 \%$ (IQR $14-58 \%)$.

\section{Mortality and Intubation/Invasive Mechanical Ventilation}

Mortality at the longest available follow-up was reported in 7 studies (1,429 subjects).21,24,27-29,31,32 Using a random effects model, HFNC compared to an oxygen therapy control (NIV or conventional $\mathrm{O}_{2}$ therapy) was associated with a decreased mortality $(\mathrm{RR}=0.72,95 \%$ CI $0.56-0.93$; $\mathrm{I}^{2}=48 \%, P=.01$ ) (Fig. 1A). Eight studies reported on 


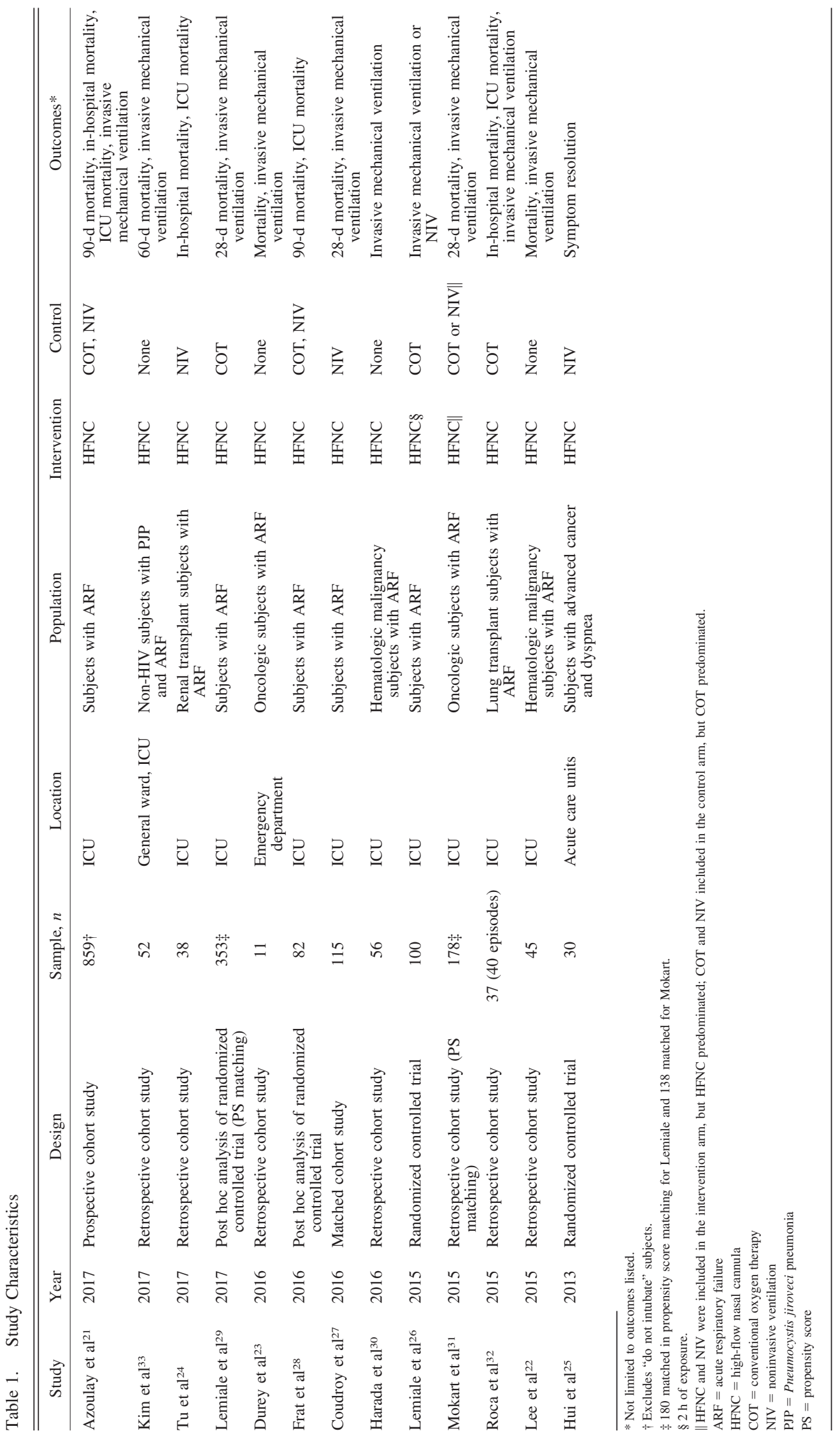




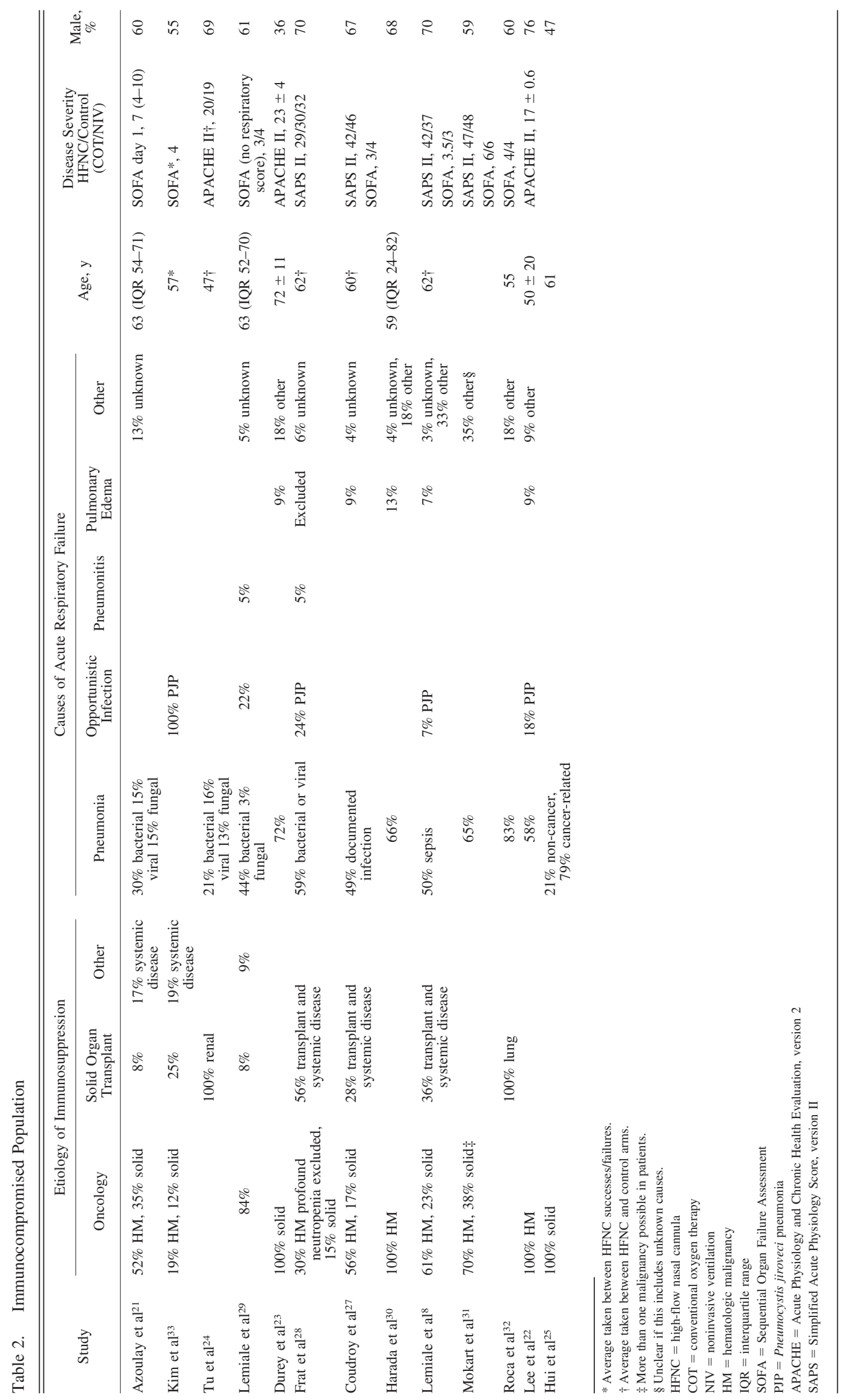




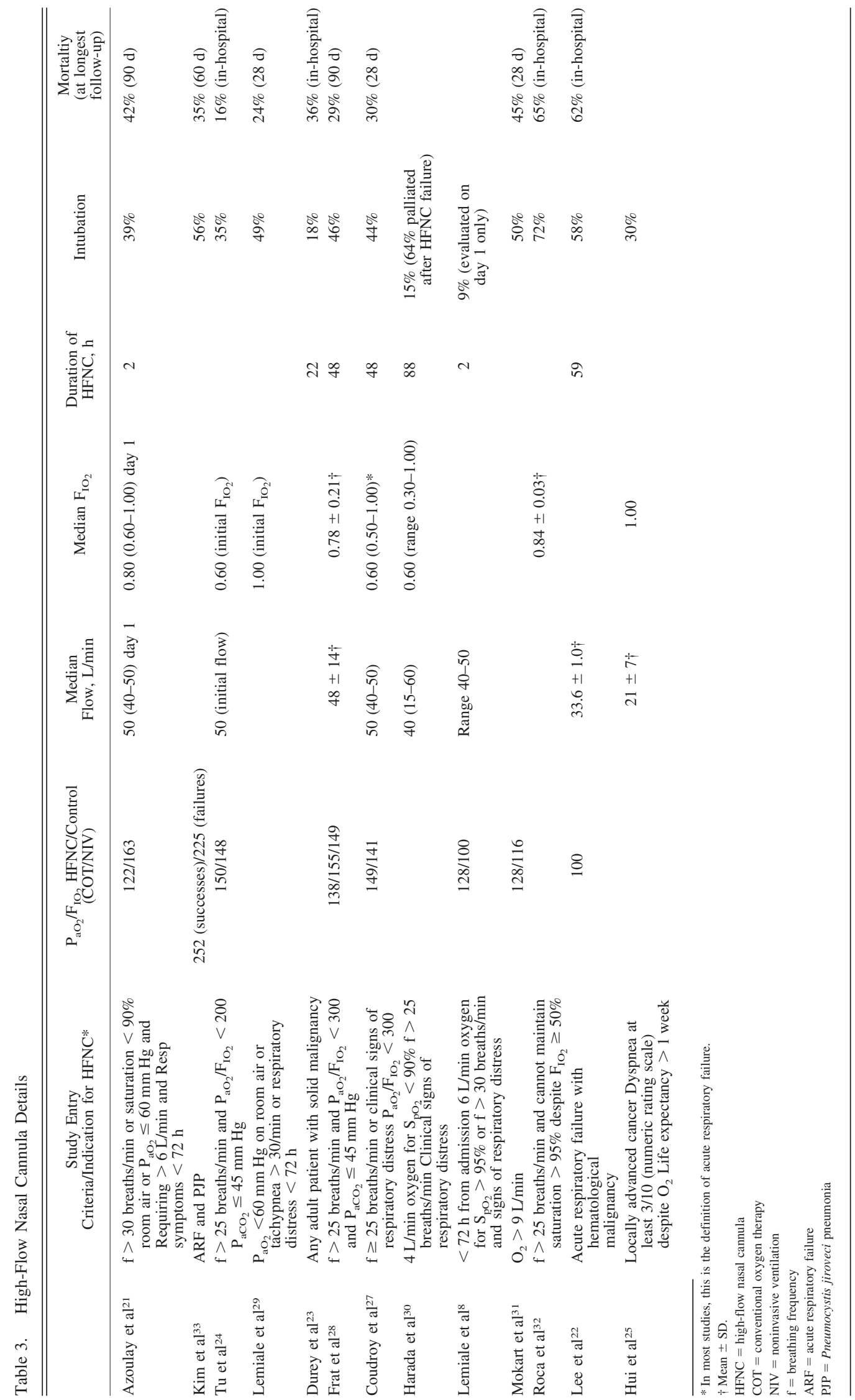




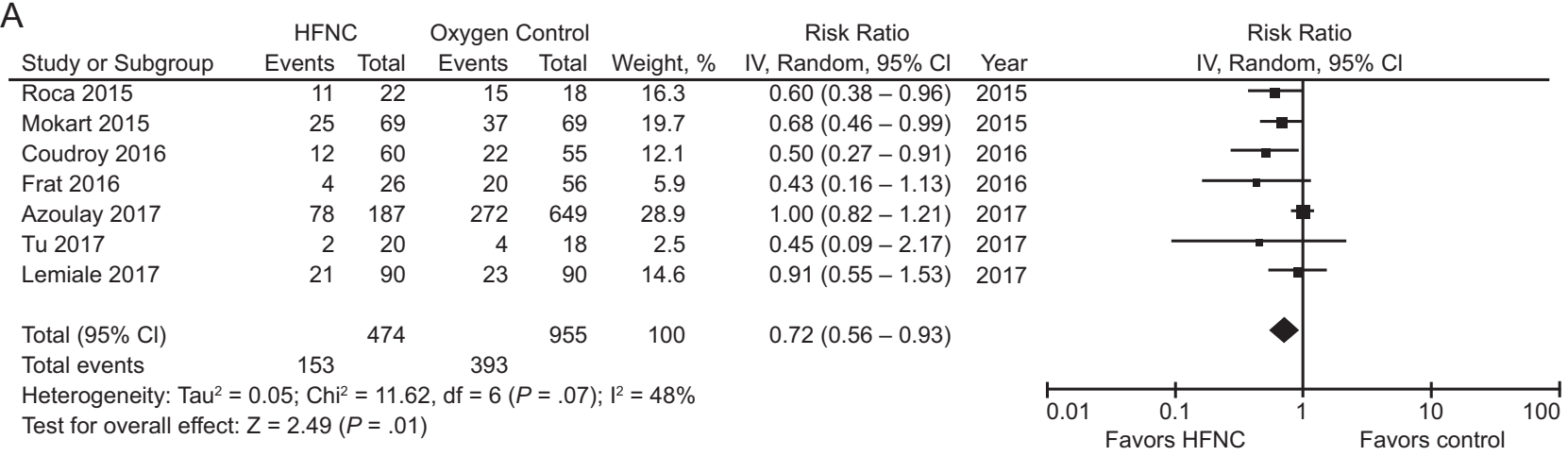

B

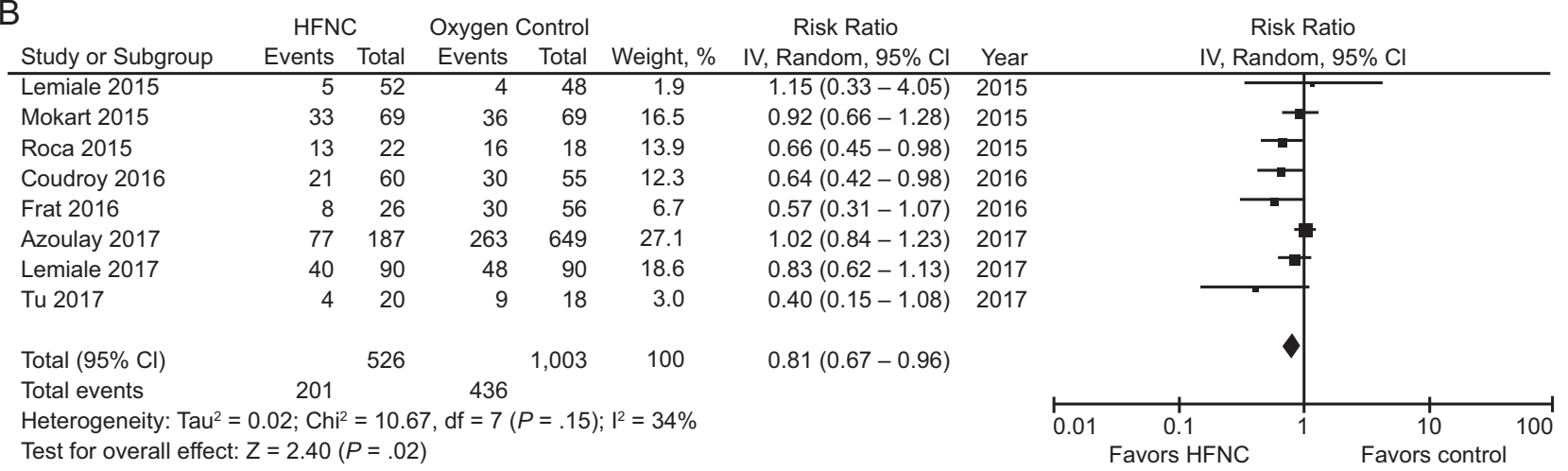

Fig. 1. A: Forest plot depicting HFNC compared to oxygen control (continuous oxygen therapy or noninvasive ventilation) on mortality across randomized trials and observational studies. Mortality time point used was $90 \mathrm{~d}$ for Azoulay et al and Frat et al, hospital mortality for Tu et al and Roca et al, and $28 \mathrm{~d}$ for Lemiale et al, Coudroy et al, and Mokart et al. The results demonstrate a decreased mortality with the use of HFNC with a risk ratio of $0.72(95 \% \mathrm{Cl} 0.56-0.93), \mathrm{I}^{2} 48 \%, P=.01$ using a random effects model. B: Forest plot depicting the effect of HFNC compared to oxygen control (continuous oxygen therapy or noninvasive ventilation) on rates of intubation across randomized trials and observational studies. The results demonstrate a decreased risk of intubation with the use of HFNC with a risk ratio of 0.81 (95\% Cl 0.67-0.96), $\mathrm{I}^{2} 34 \%, P=.02$ using a random effects model.

the need for intubation and invasive mechanical ventilation (1,529 subjects). $21,24,26-29,31,32$ HFNC was found to be associated with a decreased need for invasive mechanical ventilation compared to an oxygen control (conventional $\mathrm{O}_{2}$ therapy or NIV) $(\mathrm{RR}=0.81,95 \%$ CI $0.67-0.96$; $\mathrm{I}^{2}=34 \%, P=.02$ ) (Fig. 1B). These results were similar when restricted to RCTs and matched observational studies only (see the supplementary materials at http:// www.rcjournal.com).

Across the subgroups of oxygen therapy controls (NIV or conventional $\mathrm{O}_{2}$ therapy), HFNC compared to NIV was found to be associated with a decreased mortality (4 studies, with 545 subjects; RR $=0.60,95 \%$ CI $0.37-0.97$; $\left.\mathrm{I}^{2}=52 \%, P=.04\right)^{21,24,27,28}$ but not conventional $\mathrm{O}_{2}$ therapy ( 5 studies, with 1,097 subjects; $\mathrm{RR}=0.80,95 \% \mathrm{CI}$ $0.62-1.05 ; \mathrm{I}^{2}=49 \%, P=.11$ ) (Fig. 2). ${ }^{21,28,29,31,32}$ In the subgroup analysis comparing HFNC to NIV, there was no difference in rates of invasive mechanical ventilation (4 studies, with 545 subjects; RR $=0.67,95 \%$ CI 0.43 1.04; $\mathrm{I}^{2}=68 \%, P=.07$ ) (Fig. 3). ${ }^{21,24,27,28}$ There was also no difference in rates of invasive mechanical ventilation comparing HFNC to conventional $\mathrm{O}_{2}$ therapy (6 studies, with 1,197 subjects; $\mathrm{RR}=0.90,95 \%$ CI $0.78-1.03$; $\mathrm{I}^{2}=0 \%, P=.12$ ) (Fig. 3). ${ }^{21,26,28,29,31,32}$ The results are summarized in Table 4 and Table 5.

\section{Factors Associated With Mortality and Invasive Mechanical Ventilation}

To further evaluate predictors of mortality and invasive mechanical ventilation, we evaluated any study that conducted multivariable logistic regression analysis to characterize variables associated with increased mortality or the need for ventilation. Five studies evaluated predictors of these outcomes (Table 4). Consistent predictors of mortality or invasive mechanical ventilation included age, severity of illness score and the use of NIV or non-HFNC oxygen therapy.

\section{Discussion}

This systematic review identified 13 studies evaluating the efficacy of HFNC in 1,956 immunocompromised 


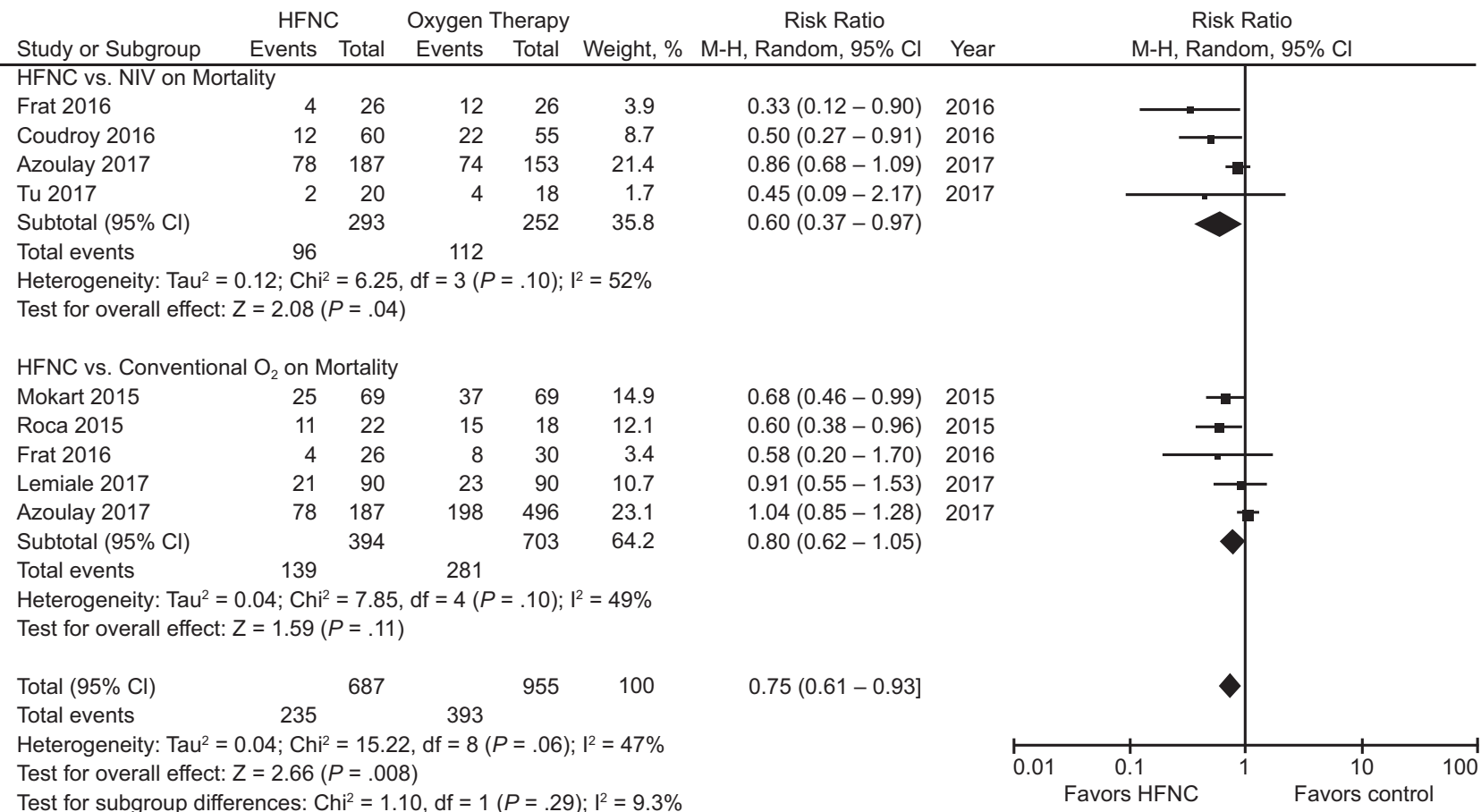

Fig. 2. Forest plot depicting HFNC compared to NIV or conventional oxygen therapy on mortality across randomized trials and observational studies. Mortality time point used was 90 days for Azoulay et al and Frat et al, in-hospital for Roca et al, and 28 days for Lemiale et al and Mokart et al. The results demonstrate a difference in mortality using a random effects model comparing HFNC vs. NIV but not HFNC vs conventional oxygen therapy.

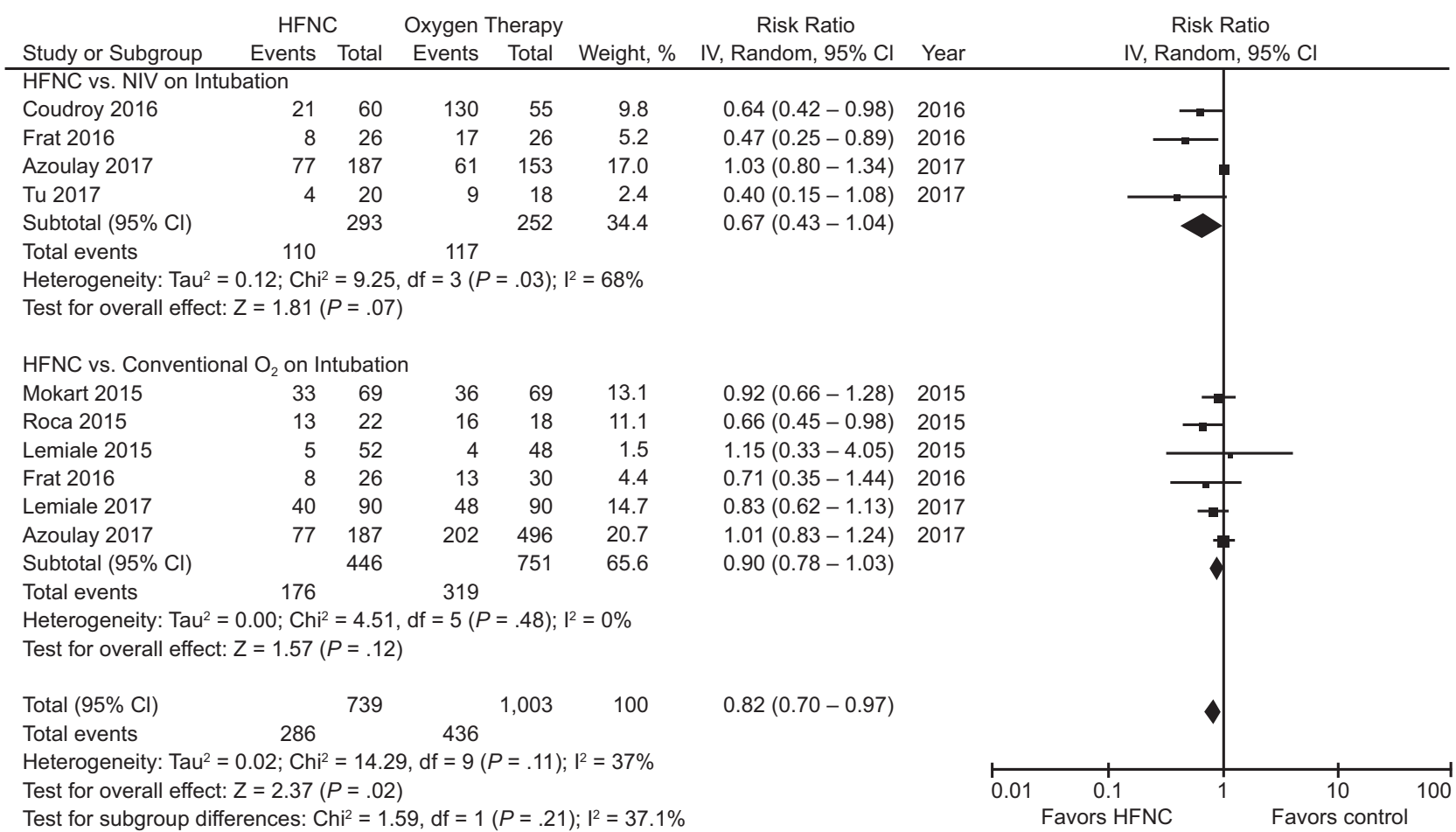

Fig. 3. Forest plot depicting HFNC compared to the comparator subgroups of NIV and conventional oxygen therapy on invasive mechanical ventilation rates across randomized trials and observational studies. No difference in rates of invasive mechanical ventilation were noted using a random effects model. 
Table 4. Predictors of High-Flow Nasal Cannula Failure

\begin{tabular}{|c|c|c|c|}
\hline Study & Outcome & Multivariable Analysis & Odds Ratio $(95 \% \mathrm{CI})$ \\
\hline \multirow[t]{8}{*}{ Azoulay et $\mathrm{a}^{21}$} & \multirow[t]{8}{*}{ In-hospital mortality } & Age & $1.18(1.09-1.27)$ \\
\hline & & Day 1 SOFA Score & $1.12(1.08-1.16)$ \\
\hline & & Day $1 \mathrm{P}_{\mathrm{aO}_{2}} / \mathrm{F}_{\mathrm{IO}_{2}}<100$ & $1.60(1.03-2.48)$ \\
\hline & & Direct admission to ICU & $0.69(0.54-0.87)$ \\
\hline & & COT & $4.16(2.91-5.93)$ \\
\hline & & HFNC & $5.54(3.27-9.38)$ \\
\hline & & NIV failure & $\begin{array}{l}3.65(2.05-6.53)(\mathrm{ref} \\
\text { no intubation) }\end{array}$ \\
\hline & & Indeterminate cause of ARF & $1.43(1.04-1.97)$ \\
\hline Kim et $\mathrm{al}^{33}$ & Invasive mechanical ventilation & SOFA score & $1.74(1.05-2.89)$ \\
\hline \multirow[t]{4}{*}{ Frat et al ${ }^{28}$} & \multirow[t]{2}{*}{ Invasive mechanical ventilation } & Age & $1.1(1.0-1.1)$ \\
\hline & & NIV as first-line treatment & $4.4(1.4-14)$ \\
\hline & \multirow[t]{2}{*}{ 90-d mortality } & Age & $1.1(1.0-1.1)$ \\
\hline & & NIV as first-line treatment & $3.3(1.2-5.0)$ \\
\hline \multirow[t]{6}{*}{ Coudroy et al ${ }^{27}$} & \multirow[t]{3}{*}{ Invasive mechanical ventilation } & SAPS II & $1.04(1.00-1.8)$ \\
\hline & & NIV as first-line treatment & $3.23(1.39-7.06)$ \\
\hline & & Vasopressors within $24 \mathrm{~h}$ of admission to ICU & $4.12(1.32-12.84)$ \\
\hline & \multirow[t]{3}{*}{ 28-d mortality } & Age & $1.03(1.00-1.07)$ \\
\hline & & NIV as first-line treatment & $2.83(1.02-7.91)$ \\
\hline & & Vasopressors within $24 \mathrm{~h}$ of admission to ICU & $3.70(1.49-9.19)$ \\
\hline Roca et $\mathrm{al}^{32}$ & Invasive mechanical ventilation & HFNC (decreased risk of invasive mechanical ventilation) & $0.11(0.02-0.69)$ \\
\hline \multicolumn{4}{|c|}{$\overline{\text { SOFA }=\text { Sequential Organ Failure Assessment }}$} \\
\hline \multicolumn{4}{|c|}{ COT $=$ conventional oxygen therapy } \\
\hline \multicolumn{4}{|c|}{ HFNC $=$ high-flow nasal cannula } \\
\hline \multicolumn{4}{|c|}{ NIV = noninvasive ventilation } \\
\hline \multicolumn{4}{|c|}{$\mathrm{ARF}=$ acute respiratory failure } \\
\hline SAPS $=$ Simplified & ogy Score, version II & & \\
\hline
\end{tabular}

Table 5. HFNC Compared to Oxygen Therapy for Acute Hypoxemic Respiratory Failure

\begin{tabular}{|c|c|c|c|c|c|}
\hline \multirow{2}{*}{$\begin{array}{l}\text { Outcomes } \\
\begin{array}{l}\text { HFNC vs oxygen control } \\
\text { on mortality }\end{array}\end{array}$} & \multicolumn{2}{|c|}{$\begin{array}{l}\text { Anticipated Absolute } \\
\text { Effects }(95 \% \mathrm{CI})\end{array}$} & \multirow{2}{*}{$\begin{array}{c}\begin{array}{c}\text { Relative Effect } \\
(95 \% \text { CI })\end{array} \\
0.72(0.56-0.93)\end{array}$} & \multirow{2}{*}{$\begin{array}{c}\begin{array}{c}\text { Participants, } n \\
\text { (Studies, no.) }\end{array} \\
\begin{array}{c}1,429 \text { (7 RCT, post hoc RCTs, } \\
\text { matched observational studies, } \\
\text { observational studies studies) }\end{array}\end{array}$} & \multirow{2}{*}{$\begin{array}{c}\begin{array}{c}\text { Certainty } \\
\text { of Evidence }\end{array} \\
\text { Moderate }\end{array}$} \\
\hline & 412 per 1,000 & 296 per $1,000(230-383)$ & & & \\
\hline $\begin{array}{l}\text { HFNC vs oxygen control } \\
\text { on invasive mechanical } \\
\text { ventilation }\end{array}$ & 435 per 1,000 & 352 per $1,000(291-417)$ & $0.81(0.67-0.96)$ & $\begin{array}{l}1,529 \text { ( } 8 \text { RCT, post hoc RCTs, } \\
\text { matched observational studies, } \\
\text { observational studies) }\end{array}$ & Moderate \\
\hline \multicolumn{6}{|c|}{$\begin{array}{l}\text { The population was immunocompromised subjects with acute hypoxemic respiratory failure. } \\
\text { HFNC = high-flow nasal cannula } \\
\text { RCT }=\text { randomized controlled trial }\end{array}$} \\
\hline
\end{tabular}

subjects with AHRF. The evidence base to date includes 4 RCTs, 8 retrospective studies, and, most recently, the largest study to date, a prospective observational cohort study. ${ }^{21}$ Intubation and mortality rates were $46 \%$ and $36 \%$, respectively. In our exploratory analysis, we found that mortality and invasive mechanical ventilation were decreased with the use of HFNC compared to any oxygen therapy control (ie, NIV or conventional $\mathrm{O}_{2}$ therapy). Across the oxygen therapy subgroups, HFNC was associated with a decreased mortality compared to NIV but not compared to conventional $\mathrm{O}_{2}$ therapy. No differences in invasive mechanical ventilation were seen in the subgroup analyses comparing HFNC to NIV or HFNC to conven- tional $\mathrm{O}_{2}$ therapy. Consistent predictors of mortality and invasive mechanical ventilation noted across 5 studies using multivariable logistic regression analysis were age, severity of illness, and NIV (or non-HFNC oxygen therapy).

This is the largest systematic review and meta-analysis to evaluate noninvasive strategies of oxygen support in the immunocompromised patient population. Our main objectives included highlighting the characteristics and evidence to date in this subset of subjects. Importantly, rates of intubation and mortality across this immunocompromised cohort have decreased compared to historic controls, highlighting the improved outcomes across immunocompro- 
mised subjects. ${ }^{1-5}$ However, the population was not homogeneous, with transplant subjects having lower rates of intubation and overall mortality compared to the oncologic and hematologic malignancy subjects. Given the higher mortality across this subset of subjects if they do progress to intubation, strategies to support them to prevent intubation remain important. This review highlights the need for higher-quality data dedicated to this particular population. Across this collected data, which was pooled for hypothesis generation, it suggests potential benefit of HFNC compared to any oxygen therapy control given the lower mortality and rates of invasive mechanical ventilation that we noted. Our results contrast with some of the findings from recently published systematic reviews comparing HFNC to conventional $\mathrm{O}_{2}$ therapy and NIV in 1,715 and 2,004 general medical/surgical subjects with AHRF, respectively. ${ }^{34,35}$ Neither analysis demonstrated a difference in the rates of invasive mechanical ventilation or mortality. A third, larger meta-analysis of $>3,000$ subjects also demonstrated results discordant with our findings. ${ }^{13}$ Investigators found a reduced rate of invasive mechanical ventilation for HFNC compared to conventional $\mathrm{O}_{2}$ therapy but not NIV, and they found no mortality difference between modalities. The difference in findings from these recent reviews may be attributable to the different populations included in other meta-analyses and our study. A large RCT of $>800$ post-cardiac surgery subjects comprised a significant proportion of each analysis. ${ }^{14}$ Postcardiac surgery AHRF is vastly different from AHRF in the immunocompromised population for several reasons, including differences in etiology and severity of AHRF. Post-cardiac surgery, cardiogenic pulmonary edema, or atelectasis may be more common, which may benefit from positive pressure delivered via either HFNC or NIV. This could, in part, explain the absence of benefit of one modality over the other.

The benefit of HFNC compared to the pooled oxygen controls may be attributable to more effective alveolar oxygen delivery, PEEP generation, humidity-induced mucociliary clearance, or dead space washout. It is possible that the results are predominantly driven by the comparison between HFNC and NIV. It is theorized that NIV could be associated with harm. One possible explanation for the finding of benefit of HFNC compared to NIV but not noted with conventional $\mathrm{O}_{2}$ therapy could be the pressure levels generated with NIV compared to pressure transmitted via HFNC. During NIV, patients may generate tidal volumes that are above those considered lung-protective ( $>8 \mathrm{~mL} / \mathrm{kg}$ tidal volume based upon ideal body weight), and this mechanism was hypothesized as a potential contributing factor in the trial by Frat and colleagues. ${ }^{12,36}$ Injurious tidal volumes could be exacerbated in the setting of spontaneous breathing, thus facilitating further ventilator-induced lung injury. ${ }^{37-40}$ This, in turn, could worsen hypoxemia and generate conditions requiring invasive mechanical ventilation. It is possible that conventional $\mathrm{O}_{2}$ therapy may not precipitate lung injury in the same way as NIV. The survival benefit seen in the HFNC versus NIV analysis may further support the argument of injurious ventilation during NIV. In one study, tidal volumes $1 \mathrm{~h}$ after initiation of NIV were $11 \mathrm{~mL} / \mathrm{kg}$ across those who died compared to $7.6 \mathrm{~mL} / \mathrm{kg}$ across those who survived, and half of the subjects on NIV had a tidal volume of $\geq 9.5 \mathrm{~mL} / \mathrm{kg} .{ }^{28}$ Immunocompromised patients typically present to the ICU with higher illness severity and multiple organ dysfunction ${ }^{5}$ and are therefore at higher risk of ventilation-associated lung injury, potentially exacerbated by injurious tidal volumes during NIV. A further hypothesis could be that oxygen therapy control groups (NIV or conventional $\mathrm{O}_{2}$ therapy) may delay the identification of the etiology for respiratory failure due to the time needed to obtain computed tomography or fiberoptic imaging if indicated, leading to a higher risk of indeterminant cause of AHRF. ${ }^{21}$ Indeterminant causes of AHRF has been shown to be associated with increased mortality. Given the small numbers, it remains unclear whether there was a higher proportion of unknown causes of AHRF in the oxygen therapy controls compared to the HFNC group. Additionally, the oxygen therapy control groups, especially NIV, could lead to an interruption in important ICU interventions such as feeding and mobilization, which may be particularly important in the immunocompromised population.

Strengths of our review include that this is the largest study to evaluate the evidence to date in this subset of subjects and to explore the potential differential impact of noninvasive oxygenation strategies on a unique critically ill population. This review, however, has several limitations. First, there was a small number of high-quality studies included in the meta-analysis, which increases the risk of bias. We included the totality of the literature (ie, RCTs and observational studies) in an attempt to utilize important subgroups or post hoc analyses to conduct our exploratory analysis. Given this expected limitation, we also conducted a series of sensitivity analyses of the "higher-quality" studies (ie, RCTs and observational studies with matching) and evaluated the results of multivariate analyses across the subset of studies, adjusting for confounders. These analyses demonstrated similar results compared to our primary analysis. Second, heterogeneity exists with respect to the underlying immunocompromised population (eg, oncology and transplant), definitions of AHRF, indication for therapy, duration of therapy, administration of noninvasive oxygen strategies, and criteria for intubation. However, despite these differences, the signal of effect was similar across most studies. Third, various modalities of NIV currently exist; however, no study reported on the use of face-tent oxygen delivery or more restrictive tidal vol- 
ume compared to the modalities explored. ${ }^{41}$ These limitations and the results of this review support the need for larger studies with homogenous inclusion criteria. The results of this systematic review are meant to be hypothesisgenerating and to highlight the characteristics across this population of AHRF. Future study will necessitate larger RCTs specifically enrolling immunocompromised subjects to compare conventional $\mathrm{O}_{2}$ therapy, NIV, and HFNC head to head.

\section{Conclusion}

HFNC is a unique oxygen-delivery modality that holds theoretical promise for the treatment of AHRF in immunocompromised patients. However, the current body of literature demonstrates that there is a paucity of high-quality data in this specific population to guide evidence-based therapy. In our exploratory analysis, the data suggest that HFNC may prevent mortality and invasive mechanical ventilation in selected settings; however, this remains a hypothesis that needs to be further evaluated with higherquality data dedicated to this population. This analysis strongly states the need for further research with clinical and physiological studies, including larger RCTs specifically enrolling immunocompromised subjects to more clearly elucidate the benefit of HFNC in this population.

\section{REFERENCES}

1. Azoulay E, Mokart D, Pene F, Lambert J, Kouatchet A, Mayaux J, et al. Outcomes of critically ill patients with hematologic malignancies: prospective multicenter data from France and Belgium-a groupe de recherche respiratoire en reanimation onco-hematologique study. J Clin Oncol 2013;31(22):2810-2818.

2. Azevedo LCP, Caruso P, Silva UVA, Torelly AP, Silva E, Rezende E, et al. Outcomes for patients with cancer admitted to the ICU requiring ventilatory support: results from a prospective multicenter study. Chest 2014;146(2):257-266.

3. Adda M, Coquet I, Darmon M, Thiery G, Schlemmer B, Azoulay E. Predictors of noninvasive ventilation failure in patients with hematologic malignancy and acute respiratory failure. Crit Care Med 2008; 36(10):2766-2772.

4. Molina R, Bernal T, Borges M, Zaragoza R, Bonastre J, Granada $\mathrm{RM}$, et al. Ventilatory support in critically ill hematology patients with respiratory failure. Crit Care 2012;16(4):R133.

5. Azoulay E, Lemiale V, Mokart D, Pene F, Kouatchet A, Perez P, et al. Acute respiratory distress syndrome in patients with malignancies. Intensive Care Med 2014;40(8):1106-1114.

6. Hilbert G, Gruson D, Vargas F, Valentino R, Gbikpi-Benissan G, Dupon $\mathrm{M}$, et al. Noninvasive ventilation in immunosuppressed patients with pulmonary infiltrates, fever, and acute respiratory failure. N Engl J Med 2001;344(7):481-487.

7. Antonelli M, Conti G, Bufi M, Costa MG, Lappa A, Rocco M, et al. Noninvasive ventilation for treatment of acute respiratory failure in patients undergoing solid organ transplantation: a randomized trial. JAMA 2000;283(2):235-241.

8. Lemiale V, Mokart D, Resche-Rigon M, Pene F, Mayaux J, Faucher E, et al. Effect of noninvasive ventilation vs oxygen therapy on mortality among immunocompromised patients with acute respira- tory failure: a randomized clinical trial. JAMA 2015;314(16):17111719.

9. Liu J, Bell C, Campbell V, DeBacker J, Tamberg E, Lee C, et al. Noninvasive ventilation in patients with hematologic malignancy. J Intensive Care Med 2017 [Epub ahead of print] doi: 10.1177/ 0885066617690725 .

10. Huang HB, Xu B, Liu GY, Lin JD, Du B. Use of noninvasive ventilation in immunocompromised patients with acute respiratory failure: a systematic review and meta-analysis. Crit Care 2017;21(1):4.

11. Wang T, Zhang L, Luo K, He J, Ma Y, Li Z, et al. Noninvasive versus invasive mechanical ventilation for immunocompromised patients with acute respiratory failure: a systematic review and metaanalysis. BMC Pulm Med 2016;16(1):129.

12. Frat JP, Thille AW, Mercat A, Girault C, Ragot S, Perbet S, et al. High-flow oxygen through nasal cannula in acute hypoxemic respiratory failure. N Engl J Med 2015;372(23):2185-2196.

13. Ni YN, Luo J, Yu H, Liu D, Ni Z, Cheng J, et al. Can high-flow nasal cannula reduce the rate of endotracheal intubation in adult patients with acute respiratory failure compared with conventional oxygen therapy and noninvasive positive pressure ventilation? A systematic review and meta-analysis. Chest 2017;151(4):764-775.

14. Stephan F, Barrucand B, Petit P, Rezaiguia-Delclaux S, Medard A, Delannoy B, et al. High-flow nasal oxygen vs noninvasive positive airway pressure in hypoxemic patients after cardiothoracic surgery: a randomized clinical trial. JAMA 2015;313(23):2331-2339.

15. Nishimura M. High-flow nasal cannula oxygen therapy in adults. J Intensive Care 2015;3(1):15.

16. Nishimura M. High-flow nasal cannula oxygen therapy in adults: physiological benefits, indication, clinical benefits, and adverse effects. Respir Care 2016;61(4):529-541.

17. Higgins JP, Altman DG, Gotzsche PC, Juni P, Moher D, Oxman AD, et al. The Cochrane Collaboration's tool for assessing risk of bias in randomised trials. BMJ 2011;343:d5928.

18. Wells G, Shea B, O'Connell D, Peterson J, Welch V, Losos M, et al. The Newcastle-Ottawa Scale (NOS) for assessing the quality of nonrandomised studies in meta-analyses. Ottawa: Ottawa Hospital Research Institute; 2009.

19. DerSimonian R, Laird N. Meta-analysis in clinical trials. Control Clin Trials 1986;7(3):177-188

20. Higgins JP, Thompson SG, Deeks JJ, Altman DG. Measuring inconsistency in meta-analyses. BMJ 2003;327(7414):557-560.

21. Azoulay E, Pickkers P, Soares M, Perner A, Rello J, Bauer PR, et al. Acute hypoxemic respiratory failure in immunocompromised patients: the Efraim multinational prospective cohort study. Intensive Care Med 2017;43(12):1808-1819.

22. Lee HY, Rhee CK, Lee JW. Feasibility of high-flow nasal cannula oxygen therapy for acute respiratory failure in patients with hematologic malignancies: a retrospective single-center study. J Crit Care 2015;30(4):773-777

23. Durey A, Kang S, Suh YJ, Han SB, Kim AJ. Application of highflow nasal cannula to heterogeneous condition in the emergency department. Am J Emerg Med 2017;35(8):1199-1201.

24. Tu G, He H, Yin K, Ju M, Zheng Y, Zhu D, et al. High-flow nasal cannula versus noninvasive ventilation for treatment of acute hypoxemic respiratory failure in renal transplant recipients. Transplant Proc 2017;49(6):1325-1330.

25. Hui D, Morgado M, Chisholm G, Withers L, Nguyen Q, Finch C, et al. High-flow oxygen and bilevel positive airway pressure for persistent dyspnea in patients with advanced cancer: a phase II randomized trial. J Pain Symptom Manage 2013;46(4):463-473.

26. Lemiale V, Mokart D, Mayaux J, Lambert J, Rabbat A, Demoule A, et al. The effects of a 2-h trial of high-flow oxygen by nasal cannula versus Venturi mask in immunocompromised patients with hypox- 


\section{HFNC In IMMUNOCOMPROMISED SUbJeCtS}

emic acute respiratory failure: a multicenter randomized trial. Crit Care 2015;19:380.

27. Coudroy R, Jamet A, Petua P, Robert R, Frat JP, Thille AW. Highflow nasal cannula oxygen therapy versus noninvasive ventilation in immunocompromised patients with acute respiratory failure: an observational cohort study. Ann Intensive Care 2016;6(1):45.

28. Frat JP, Ragot S, Girault C, Perbet S, Prat G, Boulain T, et al. Effect of non-invasive oxygenation strategies in immunocompromised patients with severe acute respiratory failure: a post-hoc analysis of a randomised trial. Lancet Respir Med 2016;4(8):646-652.

29. Lemiale V, Resche-Rigon M, Mokart D, Pene F, Argaud L, Mayaux $\mathrm{J}$, et al. High-flow nasal cannula oxygenation in immunocompromised patients with acute hypoxemic respiratory failure: a groupe de recherche respiratoire en reanimation onco-hematologique study. Crit Care Med 2017;45(3):e274-e280.

30. Harada K, Kurosawa S, Hino Y, Yamamoto K, Sakaguchi M, Ikegawa $\mathrm{S}$, et al. Clinical utility of high-flow nasal cannula oxygen therapy for acute respiratory failure in patients with hematological disease. Springerplus 2016;5:512.

31. Mokart D, Geay C, Chow-Chine L, Brun JP, Faucher M, Blache JL, et al. High-flow oxygen therapy in cancer patients with acute respiratory failure. Intensive Care Med 2015;41(11):2008-2010.

32. Roca O, de Acilu MG, Caralt B, Sacanell J, Masclans JR. Humidified high flow nasal cannula supportive therapy improves outcomes in lung transplant recipients readmitted to the intensive care unit because of acute respiratory failure. Transplantation 2015;99(5):10921098.

33. Kim WY, Sung H, Hong SB, Lim CM, Koh Y, Huh JW. Predictors of high flow nasal cannula failure in immunocompromised patients with acute respiratory failure due to non-HIV pneumocystis pneumonia. J Thorac Dis 2017;9(9):3013-3022.
34. Maitra S, Som A, Bhattacharjee S, Arora MK, Baidya DK. Comparison of high-flow nasal oxygen therapy with conventional oxygen therapy and noninvasive ventilation in adult patients with acute hypoxemic respiratory failure: A meta-analysis and systematic review. J Crit Care 2016;35:138-144.

35. Liesching TN, Lei Y. Efficacy of high-flow nasal cannula therapy in intensive care units. J Intensive Care Med 2017 [Epub ahead of print] doi: 10.1177/0885066616689043.

36. Brower RG, Matthay MA, Morris A, Schoenfeld D, Thompson BT, Wheeler A. Ventilation with lower tidal volumes as compared with traditional tidal volumes for acute lung injury and the acute respiratory distress syndrome. N Engl J Med 2000;342(18):1301-1308.

37. Brochard L. Ventilation-induced lung injury exists in spontaneously breathing patients with acute respiratory failure: yes. Intensive Care Med 2017;43(2):250-252.

38. Amato MB, Meade MO, Slutsky AS, Brochard L, Costa EL, Schoenfeld DA, et al. Driving pressure and survival in the acute respiratory distress syndrome. New Engl J Med 2015;372(8):747-755.

39. Esteban A, Frutos-Vivar F, Ferguson ND, Arabi Y, Apezteguia C, Gonzalez M, et al. Noninvasive positive-pressure ventilation for respiratory failure after extubation. N Engl J Med 2004;350(24):24522460.

40. Goldstein RA, Rohatgi PK, Bergofsky EH, Block ER, Daniele RP, Dantzker DR, et al. Clinical role of bronchoalveolar lavage in adults with pulmonary disease. Am Rev Respir Dis 1990;142(2):481-486.

41. Patel BK, Wolfe KS, Pohlman AS, Hall JB, Kress JP. Effect of noninvasive ventilation delivered by helmet vs face mask on the rate of endotracheal intubation in patients with acute respiratory distress syndrome: a randomized clinical trial. JAMA 2016;315(22):24352441. 